\title{
Running head: The Link between Mental Health, Crime and Violence
}

\section{The Link between Mental Health, Crime and Violence}

\begin{abstract}
Research investigating the link between mental health, crime and violence often rely on populations that are at a high-risk of violent and criminal behaviour, such as prison inmates and psychiatric patients. As a result of this selection bias, the relationship between mental health, criminal and violent behaviour is significantly over-estimated, with mental health being incorrectly linked with violent and criminal behaviours. This study examines the relationship between mental health, violence and crime in a more representative communitybased sample. One hundred and twenty-one individuals with and without a mental health disorder reported their involvement in crime and completed an aggression questionnaire. The results revealed that there is no statistically significant difference in terms of violence and crime involvement between individuals with a mental health diagnosis and those without. Moreover, the study did not find any statistically significant associations between specific mental health disorders and specific crime offences. The findings suggest that certain mental health disorders do not strongly contribute to crime violence and involvement. Limitations and implications are discussed in detail.
\end{abstract}

Keywords: mental health; crime; violence; aggression. 


\section{Introduction}

Individuals diagnosed with a mental health disorder are accountable for a fraction of violent offenders (1\%) and are responsible for only a small percentage of societal violence and criminal behaviour (5\%) (Fazel \& Grann, 2006; Taylor, 2008; Varshney, Mahpatra, Krishnan, Gupta \& Deb, 2015 Vinkers,de Beurs, Barendregt, Rinne, \& Hoek, 2012 Walsh, Buchanan, \& Fahy, 2002; Rueve \& Welton, 2008). These findings suggest that there is not a clear established link between mental health and violent criminal behaviour, except for psychopathy (Hare, 1996; Hart, 1998). Despite this, persistent stereotypes continue to exist which often associates mental health disorders with criminal and violent behaviour; animage that is frequently reinforced through mass media outlets (Angermeyer, Dietrich, Pott \& Matschinger, 2005).

Mass media sensationalises violent crimes such as mass shootings that has been committed by an individual with a mental health illness. Their main focus is the mental health aspect, without acknowledging that most violent acts in society are carried out by someone without a mental health illness (Varshney et al., 2015). This consequentially creates, shapes and propagates negative public attitudes, beliefs and misconceptions surrounding mental health disorders and their relationship with crime and violent behaviour (Coverdale, Nairn, \& Claasen, 2001). Television characters that have a mental health disorder are frequently portrayed as being more violent in comparison to other characters without a mental health disorder (Diefenbach \& West, 2007); with one in four of those television characters portrayed as a murderer (Signorielli, 1989). Additionally, Diefenbach and West (2007) found that at least one third of characters with a mental health disorder committed at least one violent crime.

Chen and Lawrie (2018) repeated an experiment that they conducted over 15 years ago which assessed media portrayals of mental health individuals. They found 
that representations improved by including information about treatment, rehabilitation and including quotes from mental health individuals. However, over half of the newspapers that were analysed found that there was a negative tone towards individuals with mental health disorders and in $18.5 \%$ of the cases they associated mental health with violence (Chen and Lawrie, 2018). In TV shows that are praised for their mental health representation, such as Orange is the New Black, they often promote and endorse the existing stigma on mental health (Farrell, 2018). Despite the continuous efforts to improve mental health representation within the mainstream media, negative mental health portrayals are still prevalent within today's media culture.

Previous research has documented the lack of inclination that the general population has to interact and engage with individuals diagnosed with a mental health disorder (Chung, Chen \& Liu, 2001, Silton, Flannelly, Milstein, \& Vaaler, 2011). Furthermore, people tend to label individuals with mental health disorders as "psycho, mad, disturbed, scary and violent" (Rose, Thornicroft, Pinfold \& Kassam, 2007). These perceptions have severe consequences for people with mental health illnesses as they face discrimination and become isolated from society (Rueve \& Welton, 2008). Negative perceptions, negative attitudes and beliefs, are also endorsed by mental health professionals (Lauber, Nordt, Braunschweig and Rossler 2006; Van Dorn, Volavka, \& Johnson, 2012). In particular, mental health professionals often believe that mental health disorders are the main contributory reason of violent attacks (Ipsos MORI, 2010). Negative words such as 'dangerous' and 'threatening' are often thought of as being characteristics of people with mental health disorders (Avery et al., 2013). A recent study conducted by Olmo-Romero et al., (2018) found that mental health professionals continue to support coercive treatment and display a tendency to desire social distance from individuals with mental health disorders. 
The combination of negative media portrayals, the opinions of the general population and the opinions of mental health professionals present a rather detrimental and negative representation of individuals with mental health disorders. Efforts to reduce mental health stigma is a widespread global concern and anti-mental health stigma campaigns have attempted to increase awareness surrounding mental health disorders and the inaccurate associations with violence and crime. Current research has shown that attitudes towards mental health disorders are improving, mental healthrelated knowledge is increasing and people are becoming more tolerant towards individuals with mental health issues (Time to Change, 2015). However, these tolerant attitudes vary depending on the individual's diagnosis (Parle, 2012).

The importance of understanding the link between mental health, crime engagement and violent behaviour is important. Reliable knowledge surrounding the relationship between mental health disorders, crime engagement and violent behaviour can help to better inform public policies surrounding mental health, crime and violence. It can further contribute towards the societal aims of reducing stigma and reducing crime and violent behaviour. However, further research is needed to help provide a stable platform for necessary debates surrounding mental health, crime and violent behaviour. In order to accomplish this, the question whether mental health disorders are indeed associated with crime engagement and violent behaviour must be further clarified.

\subsection{Mental Health and Crime}

In a review conducted by Link, Andrew and Cullen (1992), it was suggested that research prior to the 1980's typically upheld the stance that there was no evidence of a link between mental health and crime. However, a growing plethora of evidence is highlighting a possible relationship between mental health and crime, with many 
scholars argue in favour of the association. In support of a link between crime engagement and mental health, Hodgins, Mednick, Brennan, Schulsinger and Engberg (1996) highlighted a relationship between psychiatric hospitalisation and criminal convictions; with mental health patients being three times more likely than the general population to be arrested (Link et al., 1992). Additionally, it was reported by the National Audit Office (2017) that 37\% of the prison population in England and Wales reported emotional and mental health problems. More than three times the amount of people with a mental health disorder are detained in prisons compared to mental health units (Fazel, Hayes, Bartellas, Clerici, \& Trestman, 2016; Torrey et al., 2010).

In a study of defendants with mental health disorders, Vinkers, de Beurs, Barendregt, Rinne and Hoek (2011) highlighted a relationship between mental health disorders and numerous types of crime. They concluded that the relationship between mental health disorders and crime were most profound for crimes relating to arson, battery, homicidal attempts and threats, sex crimes and violent crimes. Specifically, psychotic and psychiatric disorders were associated with nearly all types of crime (except rape). Developmental disorders were found to be associated with homicidal crimes and personality disorders were found to be associated with homicide and sexual crimes. In a similar study, Pondé, Caron, Mendonça, Freire \& Moreau (2014) found statistically significant relationships between mental health diagnoses and crime type within a prison population. Pondé et al. (2014) found a relationship between substance addiction with sex crimes and homicide; antisocial personality disorder with robbery, kidnapping and extortion; alcohol addiction with fraud, conspiracy, armed robbery and murder and borderline personality disorder with sex crimes. Together, these studies provide support for a link between mental health and crime engagement. At first 
glance, it appears that there is clear evidence that mental health disorders are strong risk factors for engagement in crime.

However, a commonality emerges amongst the research studies that provide evidence in favour of there being a link between mental health and crime. Both Vinkers et al. (2011) and Pondé et al. (2014) measured the relationship between mental health disorders and crime engagement rates, amongst high-risk samples such as individuals who have been hospitalised in a psychiatric unit or detained in prison. Focusing on high-risk samples consequentially provides biased and exaggerated views on the link between mental health and crime. In order to overcome such limitations, it would be useful to examine the link between mental health disorders and criminal behaviour within the community. This would provide a more reliable and representative understanding of the relationship between mental health disorders and crime. However, there has been little research conducted on the matter of those living within the general community. The current literature cannot be deemed as representative of the whole mental health population, and therefore cannot be reliably generalised to anyone beyond a mental health hospital and prison walls. Further research amongst individuals with mental health living in the community is needed, in order to provide a more reliable and appropriate view of the nexus between mental health disorders and crime engagement.

\subsection{Mental Health, Aggression and Violence}

Aggression and violence often include many forms of different behaviours (Allen \& Anderson, 2017) ranging from minor behaviours (name calling), serious behaviours (hitting or punching) and to severe behaviours (stabbing or killing). Link, Phelan, Bresnahan, Stueve and Pescosolido (1999) used case vignettes of individuals with a mental health condition whereby there was no mention of violent behaviour. They 
inquired as to how probable it would be for the individual to be violent. Sixty-one per cent of people believed individuals diagnosed with schizophrenia were likely to be violent, $33 \%$ felt individuals with depression were likely to be violent and between $71 \%-87 \%$ felt alcohol and cocaine dependency increased the likelihood of violent behaviour. Yang et al. (2013) in their research with college students also used vignettes and randomly assigned a diagnosis and described the prodromal symptoms. The participants held more negative stereotypes for schizophrenia and were less willing to help an individual with psychosis compared to other diagnoses. Time to Change (2015) in their report for attitudes towards mental illness revealed that $39 \%$ of the British population felt that individuals with mental health disorders were prone to violence.

Clinical studies have often reported high rates of violence, which suggests that mental health disorders increase the risk of violent behaviours. For example, Arnetz and Arnetz (2001) found that verbal aggression is very common in psychiatric wards with 70-90\% of mental health staff experiencing verbal aggression (Duxbury, 2002). Additionally, Link et al. (1992) discovered a link between psychiatric admission and violence, with former and current inpatients having an elevated rate of hitting, fighting and weapon use compared to the general population. However, the research findings may be a result of the tendency to focus on individuals receiving treatment on a psychiatric ward or detained in prisons (Duxbury, 2002; Arnetz \& Arnetz, 2001). In a review of mental health literature regarding violence and aggression, Choe, Teplin and Abram (2008) found that nearly $90 \%$ of the studies that they reviewed surrounding mental health disorders and violence consisted of patients from psychiatric hospitals.

It is possible that the high violence and aggression rates observed in psychiatric units and prisons are the result of the environment rather than the actual mental health disorder itself. A variety of factors such as the removal of rights, a lack of meaningful 
activities and inadequate staffing numbers can have an impact on aggression and violence levels. The East London NHS Foundation Trust conducted a project on quality improvement to reduce violence on psychiatric wards. The results showed that violence on psychiatric wards decreased by $50 \%$ following the implementation of a more therapeutic environment and an increase in more meaningful activities (Brown et al, 2015). These results suggest that the environment has a significant impact on violent behaviours.

A relatively small number of empirical work has attempted to investigate the relationship between mental health and violence in a more representative community-based approach. Corrigan and Watson (2005) conducted a study comparing the rates of violent behaviour amongst those with and without a mental health diagnosis living in the general community, the results found a relationship between mental health and violence. Similarly, Swanson, Holzer, Ganju and Jono (1990) concluded that there is a significant association between mental health disorders and violent behaviours, reporting a four-fold increase in violent behaviours for some mental health disorders. Despite the improvements made in regards to the sample type, it is important to note that the two studies (Corrigan \& Watson, 2005; Swanson et al., 1990) had very loosely defined definitions of violence, which could explain why mental health disorders were strongly linked with violent behaviours. Corrigan and Watson (2005) measured violence levels based on whether individuals had experienced any serious trouble with the police or law and how many times they had been involved in a physical fight whereby someone was injured and had to receive treatment. The different measures and the different definitions of violence that each research uses, creates differences in the reported rates of violence (Walsh et al., 2002). An individual that was a victim of a physical attack and as a result used self-defensive behaviours would have been classified as violent by the standards set out by Corrigan and Watson (2005). If the violent classification 
followed Corrigan and Watson (2005) pattern it could create inaccurate measurements of violent behaviour inflating and significantly overestimating the relationship between mental health disorders and violent behaviour. Furthermore, previous research (e.g.Swanson et al., 2002) painted a picture of a marginalised group of individuals with serious and disabling mental health conditions. However, upon closer examination of the results, participants that had no previous history of violence or substance abuse and had rates of violence similar to people without a mental health disorder. Previous research has not been carried out measuring violent and aggressive behaviour in individuals with mental health disorders using a standardised and reliable measurement within a community sample. 


\subsection{The Current Study}

The link between mental health, violence and crime has been over-estimated and may be unrepresentative of reality due to several factors which include imprecise definitions of violence and unrepresentative population samples. The purpose of the current study was to contribute to the debate surrounding the nexus between mental health, crime and violence and to counteract the stigmatisation of mental health by challenging some of the existing misconceptions and stereotypes. The current study attempted to address the gaps in current literature and build upon limitations from previous research by using a more representative community-based sample in conjunction with standardised means of assessment.

The current study's primary research question is whether there is a link between mental health, crime and violence and how strong that association is. Furthermore, there are several hypotheses based on previous studies that will be examined (Varshney et al., 2015; Rueve \& Welton, 2008; Walsh et al., 2002),

(1) There will be no significant associations between mental health categories and crime type engagement.

(2) There will be no significant differences between individuals diagnosed with a mental health disorder and those without a mental health disorder regarding crime engagement.

(3) There will be no significant differences regarding violence and aggression levels between those with and without mental health.

\section{Method}

\subsection{Sample}

In this study, a sample of 121 participants $(\mathrm{N}=121)$ completed the questionnaire. Some participants did not complete all the questions and the number of participants varies 
across analysis. The age of the participants ranged from 18 to 65 years old $(\mathrm{M}=32.23$, SD = 9.22) and included $20(16.5 \%)$ males, $98(81 \%)$ females and $3(2.5 \%)$ other. In relation to ethnicity, $102(84.3 \%)$ of participants described themselves as Caucasian, 7 (5.8\%) participants described themselves as 'other', $6(5 \%)$ had mixed/multiple ethnicities, $4(4.3 \%)$ were Asian and $2(1.7 \%)$ were African American. In relation to mental health diagnosis, 57 participants $(47.1 \%)$ had a mental health diagnosis. Of these 57 participants, six (5\%) had a Schizophrenic, schizotypal or delusional disorder; $35(28.9 \%)$ had a mood (affective) disorder; 30 (24.8\%) had a neurotic, stress-related or somatoform disorder; $2(1.7 \%)$ had a behavioural syndrome; $7(5.8 \%)$ had a disorder of adult personality and behaviour; $1(0.8 \%)$ had a behavioural or emotional disorder with onset usually occurring in childhood or adolescence and $2(1.7 \%)$ had a disorder of psychological development. Participants were recruited on a voluntary basis from various mental health support groups and mental health pages on Facebook.

\subsection{Materials and Measures}

2.2.1. Definition of Mental Health Disorders. Mental health disorders were categorised in accordance to the International Classifications of Diseases, which provides clinical descriptions and diagnostic guidelines for mental health disorders (WHO 1992). Individuals were categorised according to their mental health diagnoses.

2.2.2. Definition of Aggressive and Violent Behaviour. The current study views aggression and violence on a spectrum with aggressive behaviours being less severe (such as name calling) and at one end of the spectrum, whilst violent behaviour is more serve (such as committing homicide) and at the opposite end of the spectrum (Allen \& Anderson, 2017). As such, the terms 'violence' and 'aggression' are used interchangeably throughout. 
2.2.3. Questionnaire. The questionnaire was comprised of three components, including demographic questions, the self-reported violent offending questionnaire (Oleson \& Chappell, 2012) and the Buss and Perry (1992) aggression questionnaire.

2.2.4. Demographic questions. The questionnaire consisted of demographic questions and questions surrounding mental health diagnosis, arrest and convictions. Responses to these questions were dichotomous (yes/no) (see appendix).

2.2.5. Self-reported violent offending questionnaire. The current study employed an adapted and shortened version of the self-reported violent offending questionnaire devised by Oleson and Chappell (2012) to avoid missing responses and incorrect reporting due to length. As such, only 42 of the 72 original offences were included and used dichotomous responses (yes/no) rather than quantifiable responses. The self-reported violent offending questionnaire had a high level of internal consistency, as determined by a Cronbach's alpha of 0.903 . The self-reported violent offending questionnaire consisted of 42 questions relating to engagement in different types of crime across five crime offence categories which included property offences (Cronbach's $\alpha=0.812$ ); sexual offences (Cronbach's $\alpha=0.553$ ); drug offences (Cronbach's $\alpha=0.758)$; violent offences (Cronbach's $\alpha=0.6$ ) and vehicular offences (Cronbach's $\alpha=0.638)$. In accordance with Hilton, Brownlow, McMurray and Cozens (2004), the questionnaire as a whole and all the five crime subscales had moderate to high reliability ( 0.70 to 0.90 shows high reliability and 0.50 to 0.70 shows moderate reliability).

2.2.6. Buss and Perry (1992) aggression questionnaire. The questionnaire included Buss and Perry's (1992) aggression questionnaire. The questionnaire had a high level of internal consistency, as determined by a Cronbach's alpha of 0.907 . The Buss and Perry (1992) aggression questionnaire assesses four subscale measurements 
of aggression including physical aggression (Cronbach's $\alpha=0.842$ ), verbal aggression (Cronbach's $\alpha=0.793)$, hostility (Cronbach's $\alpha=0.846)$ and anger (Cronbach's $\alpha=$ 0.740). In accordance with Hilton et al. (2004), all the subscales had high reliability ( 0.70 to 0.90 shows high reliability). The 29 items were randomly arranged. Responses to the questionnaire were ranked on a scale of one (extremely uncharacteristic of me) to five (extremely characteristic of me). Total scores for each subcategory was computed by summing the appropriate items together. Each participant received a physical aggression score, a verbal aggression score, a hostility score and an anger score. For an overall aggression score, the four subscales were totalled.

\subsection{Procedure}

An anonymous link for the online questionnaire was posted to mental health groups and Facebook pages to ensure participation was anonymous and that confidentiality was upheld.

\subsection{Data Analysis}

The analysis was conducted using descriptive statistics and as the data were not normally distributed, non-parametric analyses were used (Mann-Whitney U, ChiSquare and Fisher Exact). All tests were two-tailed with the alpha level set at $p<0.05$. Missing data for the Buss and Perry Aggression Scale was dealt with by using missing data analysis. Little's test indicated that the values were missing at random $(p<.05)$ so expectation maximisation analyses was conducted to calculate the estimated values of the missing data.

\section{Results}

\subsection{Mental Health and Crime Engagement}

Multiple chi-square test of association was conducted to examine the link between mental health disorder and crime engagement. Firstly, chi-square analysis was 
conducted to examine the associations between mental health status (diagnosed/not diagnosed), criminal history (arrest and conviction rates) and rates of engagement across multiple crime offences (property, sexual, vehicular, drug and violent offences). Secondly, chi-square analysis was conducted to assess the association between mental health categories and crime engagement rates across multiple offences.

3.1.1. Mental Health Status and Crime Engagement. In relation to arrest rates, only a small percentage of the participants had been previously arrested or convicted. Only $10(17.5 \%)$ participants diagnosed with a mental health condition and eight (12.5\%) participants without a mental health condition have been arrested on at least one occasion. Chi-square analysis revealed no significant association $p>.05$. between mental health status and being arrested in relation to conviction rates, six (10.5\%) participants diagnosed with a mental health condition and three (4.7\%) participants without a mental health condition were convicted of at least one crime. Chi-square analysis did not find a significant association $(p>.05)$ between mental health status and being convicted of a crime.

3.1.2. Property Offences. In regards to property offences, 40 participants (70.2\%) who had a mental health diagnosis admitted to committing at least one property offence whilst 46 participants (71.9\%) without a mental health disorder committed a property offence. Chi-square analysis revealed that there were no significant associations between mental health status and engagement in property offences $(p>.05)$.

3.1.3. Sexual Offences. From the sample, 35 participants $(61.4 \%)$ diagnosed with a mental health condition and 30 participants (46.9\%) without a mental health condition committed at least one sexual offence. Chi-square analysis revealed no significant associations between mental health status and engagement in sexual offences $(p>.05)$. 
3.1.4. Drug Offences. In total, forty-eight participants (84.2\%) were diagnosed with a mental health condition and 55 participants $(85.9 \%)$ without a mental health diagnosis committed at least one drug offence. Chi-square analysis revealed no significant associations between mental health status and engagement in drug offences $(p>.05)$.

3.1.5. Vehicular Offences. Twenty-five participants (43.9\%) that were diagnosed with a mental health condition and 22 participants (34.4\%) that had not been diagnosed with a mental health admitted to committing a vehicular offence. Chi-square analysis revealed no significant associations between mental health status and engagement in vehicular offences $(p>.05)$.

3.1.6. Violent Offences. Twelve participants $(21.1 \%)$ with a mental health condition committed at least one violent offence, compared to five participants $(7.8 \%)$ without a mental health condition. Chi-square analysis revealed that there was a statistically significant association in relation to violent offences and mental health status, $(\chi 2=0.49, p<.005)$. However, subsequent chi-square analysis was conducted for the singular violent offences and revealed that none of the violent crimes were significant.

\subsubsection{The Link Between Specific Mental Health Disorders and Crime Offences.}

Chi-square analysis was conducted to measure the association between specific mental health disorder categories and engagement in specific crime types (property, vehicular, sexual, drug and property offences). Chi-square analysis revealed no significant associations between any of the mental health disorder categories and any of the crime offence categories.

\subsection{The Link Between Mental Health Status and Violence}

Mann-Whitney $U$ tests were conducted to determine if there were any differences in the aggression and violence scores between participants that were diagnosed with a mental health disorder and participants without a mental health disorder 
The Mann-Whitney U tests revealed no significant differences in anger scores for those with a mental health diagnosis and without a mental health diagnosis $(p>.05)$. Additionally, there was no significant difference in the physical violence scores for those with a mental health diagnosis and without a mental health diagnosis $(p>.05)$. In relation to verbal violence scores, those with a mental health disorder did not differ significantly from those without a mental health disorder $(p>.05)$. Similarly, no significant difference was found in relation to hostility scores between those diagnosed with mental health and those without a mental health diagnosis ( $p>.05)$. Regarding the overall violence and aggression scores, no significant differences were found between those with a mental health diagnosis and those without a mental health diagnosis ( $p>.05)$ (see table 1 for a summary of results).

\section{Place Table 1 Here}

\section{Discussion}

Despite an increase in knowledge, understanding and continuous efforts to improve public attitudes, beliefs and perceptions towards individuals living with a mental health disorder, negative stereotypes still exist which continue to intertwine mental health disorders with negative connotations such as violence, criminality and dangerousness (Rose et al., 2007). Media and scholarly literature often exaggerate the magnitude of the relationship between mental health, crime and aggressive behaviours through focusing on high-risk samples (Choe, Teplin, \& Abram, 2009).

The relationship between mental health disorders, crime and violence is often overestimated, ultimately serving to propagate negative stereotypes surrounding mental health (Ahonen, Loeber, \& Brent, 2017). It was hypothesised that there will be no significant differences in crime engagement levels between individuals with and without a mental health diagnosis. In addition, there would be no significant associations between mental health categories and engagement across different crime offences. Finally, that there would be no 
differences between individuals with and without a mental health diagnosis in regards to aggression and violence levels.

\subsection{Mental Health and Crime Engagement}

Consistent with the first hypothesis of the current study, relatively small differences were observed between individuals with and without mental health disorders in relation to crime engagement. The arrest and conviction rates of those with a mental health disorder did not differ significantly in comparison to those without a mental health disorder. The findings surrounding mental health disorders and crime engagement suggest that there is not a significant link between being diagnosed with a mental health disorder and becoming involved in crime. These findings contradict the majority of the literature (Pondé et al., 2014; Vinkers et al., 2011) that is available today surrounding mental health and crime. Research has shown that mental health is not a large predictor of crime engagement. In fact, only asmall percentage of crimes that are committed by individuals with mental illness can be directly related to their psychiatric symptoms (Peterson, Skeem, Hart, Vidal, \& Keith, 2010; Peterson, Skeem, Kennealy, Bray, \& Zvonkovic, 2014).

In relation to rates of engagement in property crimes, sex crimes, vehicular crimes and drug crimes it did not differ between those diagnosed with a mental health disorder and the individuals without. The only significant difference observed in relation to mental health status (diagnosed/not diagnosed) was the rate of engagement in violent crimes, with more individuals diagnosed with a mental health admitting to committing a violent offence compared to individuals with a mental health diagnosis. Fazel et al (2009) had similar results with schizophrenic participants being more violent than participants from the general population. Further analysis of the singular violent crime engagement rates revealed that there was no difference regarding mental health status. Therefore, there was very little difference between violent crime engagement rates between those with and without mental 
health. The statistical significance relating to the differences in violent crime engagement amongst those with and without a mental health diagnosis obtained within the study can be attributed to the small sample size (Faber \& Fonseca, 2014). Consequently, confirmation of the results with a larger sample size is advisable for future research. Overall, the findings observed in the current study contradict past literature (Hodgins, Mednick, Brennan, Schulsinger \& Engberg, 1996; Link et al., 1992), which depicts a strong relationship between crime and mental health disorders. The current research makes a unique contribution to the existing limited literature.

Secondly, with regards to the predictions surrounding the relationship between individual mental health categories and crime offences, the findings support the second hypothesis. The current study found that there were no significant associations between mental health categories and crime offences. Much of the previous literature surrounding this relationship has found significant links between mental health and crime (see Pondé et al., 2014; Vinkers et al., 2011). Therefore, the current study opposes previous studies as no evidence of a significant association between individual mental health disorders and engagement in crime offences was established.

As mentioned previously, the literature surrounding mental health and crime offence engagement heavily relies on high-risk samples such as psychiatric inpatients (Vinkers et al., 2011) and prison inmates (Pondé et al., 2014). The differences between the findings from the current study and the previous research could be the result of the sample population used, which was a community-based population . Each sample population is faced with different expectations in everyday life and the different environment they are in could either hinder or facilitate violent behaviour.

Furthermore, the results indicated that crime engagement rates across the crime offences are relatively high, regardless of mental health status. For example, $71.1 \%$ of the 
whole sample admitted to committing at least one property crime, $53.7 \%$ admitted to committing at least one sex crime and $85.1 \%$ admitted to committing a drug crime. Crime rates were relatively low for violent crimes (26.4\%) and vehicular crimes $(38.8 \%)$. The high crime engagement rates observed in the current study, which cannot be attributable to mental health disorders, suggest that there may be other risk factors that may have a stronger relationship to crime engagement than mental health disorders. Previous research has shown that there are multiple factors that contribute to crime within society. For example,young adult men of a low socioeconomic status typically commit more crimes (Laurisen, Heimer \& Lynch, 2009; Warren, Hurt, \& Loper, 2002; Swanson et al., 1990). Therefore, the findings further support that mental health diagnosis cannot be considered as a strong contributor of criminal behaviour.

\subsection{Mental health, Violence and Aggression}

Regarding the relationship between mental health and violence, the results support the third hypothesis that there is no difference in regards to the violence/aggression levels between individuals with and without a mental health diagsnosis. . Specifically, when comparing the aggression scores obtained within the current study and the average scores obtained by Buss and Perry (1992), the majorityof the averages for the subscales of aggression were either within the normal range or below average.Consequently, the results obtained in the current study suggest that mental health individuals are not likely to be more violent than individuals without a mental health disorder (Walsh, Buchanan, \& Fahy, 2002; Rueve \& Welton, 2008).

However, the results were inconsistent with the existing literature surrounding mental health, violence and aggression. Current literature often depicts a strong relationship between mental health disorder and violent/aggressive behaviours and embeds mental health disorders with concepts of dangerousness, violence and aggressiveness both in everyday life and in 
psychiatric units (Arnetz \& Arnetz, 2001; Duxbury, 2002; Ryan \& Poster, 1993, Newton, Elbogen, Brown, Snyder, \& Barrick 2012, Torrey, 2011). The differences in the findings between the current study and previous literature could again be the result of the sample type used. There were no significant results that align with the two current community studies surrounding mental health and violence. Both Corrigan and Watson (2005) and Swanson et al. (1990) found high rates of violence within a community sample. However, perhaps, both Corrigan and Watson (2005) and Swanson et al., (1990) measured violence in an imprecise way, resulting in mental health disorders being wrongly intertwined with violence. This research could be considered more reliable as a more valid and standardised measure was used to measure aggressive and violent behaviour. The homogeneity of research findings between the current study and previous research could reflect the different conceptualisations and measurements of violent and aggressive behaviours.

\subsection{Limitations and directions for future research}

As with all research, the findings should be interpreted within the constraints of the limitations. Firstly, It is important to note that the study relied on self-report data and did not corroborate crime engagement rate using criminal records, as the participants completed the questionnaire anonymously. As criminal behaviour is considered socially undesirable behaviours, there is the possibility that the participants may have under reported their crime engagement (Coid, Yang, Tyrer, Roberts, \& Ullrich, 2006). However, self-report data can capture crimes that have not been included in crime statistics, if the individuals have not been arrested or prosecuted for their crime and provide a more in-depth picture of the relationship between mental health disorders and crime engagement. Self- reporting has been used to collect data over the years in research exploring mental health stigma, perceptions of mental health both from the general public and individual with mental health issues (Link, Phelan, Bresnahan, Stueve, \& Pescosolido, 1999, Reavley \& Jorm, 2011, Wood, Birtel, Alsawy, Pyle 
\& Morrison, 2014). That being stated, potential biased responses are a limitation. However, as with most research, the researchers are forced to take responses as truthful unless there are apparent deceitful responses. Future research should aim to incorporate both official and selfreport data within a community sample to ensure the true prevalence of crime and mental health is appropriately reported.

Secondly, this project focused on mental health as an overarching concept by categorising mental health diagnosis based on ICD-10 categories rather than specific mental health disorders. As such, this method can underestimate the relationship between mental health disorders, crime engagement and aggressive/violent behaviours. For example, bipolar affective disorder and recurrent depressive disorder are both categorised under mood affective disorders in the ICD-10 but have different symptoms, characteristics and possibly different relationships with crime engagement and aggressive/violent behaviour. The same limitation could be applied to the use of categorisation of the crime offences. Such large and encompassing categorisations can hide important relationships amongst the individual crime offences and specific mental health disorders. For example, an individual with a mental health disorder may smoke marijuana for medicinal purposes but this does not imply that they are likely to engage in using more hard drugs such as cocaine or heroin. Therefore, there was limited statistical power in the results to be able todistinguish between specific mental health diagnoses and may under-estimate and impede the true understanding of the relationship between mental health disorders, crime engagement and aggressive/violent behaviour. It would be beneficial for future research to avoid conceptualising mental health and crime as broad concepts.

Thirdly, the association between mental health disorders, aggressive/violent behaviour and and engagement in criminal behaviour cannot be deemed exempt from selection bias as the current study relied on individuals from mental health support groups 
and various mental health Facebook pages. However, given that the majority of the current literature surrounding mental health, violence and crime often heavily focus on individuals that are either psychiatric inpatients (Vinkers et al., 2011) or prison inmates (Pondé et al., 2014), the current study may be considered to be more representative of the general mental health population as the sample included individuals from the general population. The final limitation is the sample size as it was separated into two smaller groups, the participants with a mental health diagnosis and those without. This could be amended in future research by recruiting more participants for each group.

Despite these limitations, the findings provide evidence that challenges the widespread, negative and persistent stereotypes and misconceptions that still exist throughout society. The current study demonstrates that crime and violence levels are clearly much lower within the general community compared to prisons and psychiatric units. As a result, the data obtained within the current study surrounding the nexus between mental health disorders, crime engagement and aggressive behaviour has numerous implications in relation to current mental health, crime and violence policies. The results highlight the importance of policymakers to acknowledge that mental health disorders is not a significant contributor to violence and criminal behaviour. Rather than focusing on reducing crimes committed by individuals with mental health disorders, it would be far more beneficial for policymakers to focus on implementing effective violence and crime reduction strategies within environments where rates are elevated such as prisons and psychiatric hospitals.

Future research could expand this current study by exploring narrative roles. Previous studies on narratives have provided valuable information to understand human behaviours across different offenders (Canter, Kaouri \& Ioannou, 2003; Ioannou, 2006; Ioannou, Canter, Youngs \& Synnott, 2015; Ioannou, Canter \& Youngs, 2017; Goodlad, Ioannou \& Hunter, 2018; Ioannou, Synnott, Lowe \& Tzani-Pepelasi, 2018; Ciesla, Ioannou \& Hammond, 2018). 
Incorporating narratives in a research where two groups of people (individuals diagnosed with a mental health disorder and those without a mental health disorder) that often are researched separately and can offer a unique insight into differences and similarities of behaviour and the narratives roles people associate with themselves.

In conclusion, the current study is a preliminary effort to further understand and clarify the link between mental health disorders, crime engagement and aggressive/violent behaviours. It is accepted that the sample size might have created boundaries for more insightful results, however, the study also functions as a pilot to larger project with a more broad and larger sample size. Future research can address such limitations by recruiting participants from various age groups; equal numbers of both genders and perhaps include a control group for exploration of any results that may occur by chance. The current findings suggest that mental health disorders cannot be considered as a strong contributor to crime engagement and violent behaviours. The findings within the study challenge the negative perceptions and inaccurate stereotypes that persist within the media, public beliefs and attitudes and in scholarly literature. It has the potential to provide support for current antistigma campaigns and to better inform public policy surrounding mental health, crime and violent behaviour. 


\section{References}

Ahonen, L., Loeber, R., \& Brent, D. A. (2017). The association between serious mental health problems and violence: some common assumptions and misconceptions. Trauma, Violence, \& Abuse, 1524838017726423.

Allen, J. J., \& Anderson, C. A. (2017). Aggression and Violence: Definitions and Distinctions. The Wiley Handbook of Violence and Aggression, 45(5), 1-14. doi:10.1002/9781119057574.whbva001.

Angermeyer, M. C., Dietrich, S., Pott, D., \& Matschinger, H. (2005). Media consumption and desire for social distance towards people with schizophrenia. European Psychiatry, 20(3), 246-250.

Arnetz, J. E., \& Arnetz, B. B. (2001). Violence towards health care staff and possible effects on the quality of patient care. Social Science \& Medicine, 52(3), 417-427. doi:10.1016/s0277-9536(00)00146-5.

Avery, J., Dixon, L., Adler, D., Oslin, D., Hackman, A., First, M., et al. (2013). Psychiatrists' attitudes toward individuals with substance use disorders and serious mental illness. Journal of Dual Diagnosis, 9(4), 322-326. doi:10.1080/15504263.2013.835165

Brown, J., Fawzi, W., Mccarthy, C., Stevenson, C., Kwesi, S., Joyce, M., . . Shah, A. (2015). Safer Wards: Reducing violence on older peoples mental health wards. BMJ Quality Improvement Reports, 4(1). doi:10.1136/bmjquality.u207447.w2977.

Buss, A. H., \& Perry, M. (1992). The aggression questionnaire. Journal of personality and social psychology, 63(3), 452. http://dx.doi.org/10.1037/0022-3514.63.3.452.

Canter, D., Kaouri, C., \& Ioannou, M. (2003). The facet structure of criminal narratives. In L. Shlomit \& D. Elizur (Eds.), Facet theory: Towards cumulative social science (pp. 2738). Ljubljana, Slovenia: University of Ljubljana. 
Choe, J. Y., Teplin, L. A., \& Abram, K. M. (2008). Perpetration of Violence, Violent Victimization, and Severe Mental Illness: Balancing Public Health Concerns. Psychiatric Services, 59(2), 153-164. doi:10.1176/appi.ps.59.2.153.

Ciesla, K., Ioannou, M., \& Hammond, L. (2018). Women offenders' emotional experience of crime. Journal of Investigative Psychology and Offender Profiling, 15(3), 287303. https://doi.org/10.1002/jip.1512.

Chan, B., \& Shehtman, M. (2019). Clinical risk factors of acute severe or fatal violence among forensic mental health patients. Psychiatry research.

Chen, M., \& Lawrie, S. (2017). Newspaper depictions of mental and physical health. BJ Psych Bulletin, 41, 308-313. https://doi.org/10.1192/pb.bp.116.054775

Chung, K. F., Chen, E. Y., \& Liu, C. S. (2001). University students' attitudes toward mental patients and psychiatric treatment. International Journal of Social Psychiatry, 47(2), 63-72. doi: 10.1177/002076400104700206.

Coid, J., Yang, M., Tyrer, P., Roberts, A., \& Ullrich, S. (2006). Prevalence and correlates of personality disorder in Great Britain. British Journal of Psychiatry, 188(05), 423-431. doi:10.1192/bjp.188.5.423.

Corrigan, P.W., \& Watson, A.C. (2005). Findings from the National Comorbidity Survey on the frequency of violent behavior in individuals with psychiatric disorders. Psychiatry Research, 136(2-3), 153-162. doi: 10.1016/j.psychres.2005.06.005.

Coverdale, J., Nairn, R., \& Claasen, D. (2002). Depictions of Mental Illness in Print Media: A Prospective National Sample. Australian \& New Zealand Journal of Psychiatry, 36(5), 697-700. doi:10.1046/j.1440-1614.2002.00998.x.

Diefenbach, D. L., \& West, M. D. (2007). Television and attitudes toward mental health issues: Cultivation analysis and the third-person effect. Journal of Community Psychology, 35(2), 181-195. doi:10.1002/jcop.20142. 
Duxbury, J. (2002). An evaluation of staff and patient views of and strategies employed to manage inpatient aggression and violence on one mental health unit: A pluralistic design. Journal of Psychiatric and Mental Health Nursing, 9(3), 325-337. doi:10.1046/j.1365-2850.2002.00497.x.

Eggink, E., de Waal, M. M., \& Goudriaan, A. E. (2019). Criminal offending and associated factors in dual diagnosis patients. Psychiatry research, 273, 355-362.

Faber, J., \& Fonseca, L. (2014). How sample size influences research outcomes. Dental Press Journal Of Orthodontics, 19(4), 27-29. doi: 10.1590/2176-9451.19.4.027-029.ebo

Fazel, S., \& Grann, M. (2006). The population impact of severe mental illness on violent crime. American Journal of Psychiatry, 163, 1397-1403.

Fazel, S., Gulati, G., Linsell, L., Geddes, J. R., \& Grann, M. (2009). Schizophrenia and violence: Systematic review and meta-analysis. PLoS Med, 6, e1000120. doi:10.1371/journal.pmed.1000120

Fazel, S., Hayes, A. J., Bartellas, K., Clerici, M., \& Trestman, R. (2016). Mental health of prisoners: prevalence, adverse outcomes, and interventions. The Lancet Psychiatry, 3(9), 871-881.

Farrell, A. (2018). A Critical Analysis of Violence as a Symptom of Mental Illness in Orange is the New Black. Verso: An Undergraduate Journal of Literary Criticism, 9.

Goodlad, K., Ioannou, M., \& Hunter, M. (2018). The Criminal Narrative Experience of Psychopathic and Personality Disordered Offenders. International Journal of Offender Therapy and Comparative Criminology. https://doi.org/10.1177/0306624X18808433.

Hart, S. D. (1998). The role of psychopathy in assessing risk for violence: Conceptual and methodological issues. Legal and Criminological Psychology, 3(1), 121-137. doi:10.1111/j.2044-8333.1998.tb00354.x. 
Hodgins, S., Mednick, S. A., Brennan, P. A., Schulsinger, F., \& Engberg, M. (1996). Mental disorder and crime. Evidence from a Danish birth cohort. Archives of General Psychiatry, 53(6), 489-96. doi:10.1001/archpsyc.1996.01830060031004.

Hinton, P., Brownlow, C., McMurray, I., \& Cozens B. (2004). SPSS explained. Routledge. Retrieved from www.fb4all.com/download/ebooks/statistics/SPSS\%20Explained2014.pdf.

Ioannou, M., Synnott, J., Lowe, E., \& Tzani Pepelasi, K. (2018). Applying the Criminal Narrative Experience Framework to Young Offenders. International Journal of Offender Therapy and Comparative Criminology. https://doi.org/10.1177/0306624X18774312.

Ioannou, M., Canter, D., \& Youngs, D. (2017). Criminal narrative experience: Relating emotions to offence narrative roles during crime commission. International Journal of Offender Therapy and Comparative Criminology, 61(14), 1531-1553. doi:10.1177/0306624X15625991.

Ioannou, M., Canter, D., Youngs, D., \& Synnott, J. (2015). Offenders' Crime Narratives Across Different Types of Crimes. Journal Of Forensic Psychology Practice, 15(5), 383-400.

Ioannou, M. (2006). Hero or villain? Criminals' experience of crime. ( $\mathrm{PhD}$ thesis). University of Liverpool, Liverpool.

Ipsos MORI. (2010). Violence against frontline NHS staff_research for COI on behalf of the NHS Security Management Service. London: Ipsos MORI. Retrieved from http://www.thensmc.com/dev/sites/default/files/298085\%20$\%$ 20NHS\%20Violence\%20Against\%20NHS\%20Frontline\%20Staff\%20Report.pdf. 
Lauber, C., Nordt, C., Braunschweig, C., \& Rossler, W. (2006). Do mental health professionals stigmatize their patients? Acta Psychiatrica Scandinavica, 113(S429), 51-59. doi:10.1111/j.1600-0447.2005.00718.x.

Link, B. G., Andrews, H., \& Cullen, F. T. (1992). The Violent and Illegal Behavior of Mental Patients Reconsidered. American Sociological Review, 57(3), 275. doi: $10.2307 / 2096235$.

Link, B. G., Phelan, J. C., Bresnahan, M., Stueve, A., \& Pescosolido, B. A. (1999). Public conceptions of mental illness: Labels, causes, dangerousness, and social distance. American Journal of Public Health, 89(9), 1328-1333. doi:10.2105/ajph.89.9.1328.

National Audit Office (2017). Mental health in prisons. Retrieved from https://www.nao.org.uk/wp-content/uploads/2017/06/Mental-health-in-prisons.pdf.

Newton, V. M., Elbogen, E. B., Brown, C. L., Snyder, J., \& Barrick, A. L. (2012). Clinical decision-making about inpatient violence risk at admission to a public-sector acute psychiatric hospital. Journal of the American Academy of Psychiatry and the Law Online, 40(2), 206-214.

Nordt, C., Rossler, W., \& Lauber, C. (2006). Attitudes of Mental Health Professionals q Toward People With Schizophrenia and Major Depression. Schizophrenia Bulletin, 32(4), 709-714. doi:10.1093/schbul/sbj065.

Novaco, R. W. (2011). Anger dysregulation: Driver of violent offending. Journal of Forensic Psychiatry \& Psychology, 22, 650-668. doi:10.1080/14789949.2011.617536

Oleson, J. C., \& Chappell, R. (2012). Self-Reported Violent Offending Among Subjects with Genius-Level IQ Scores. Journal of Family Violence, 27(8), 715-730. doi:10.1007/s10896-012-9468-7. 
Olmo-Romero, F. D., González-Blanco, M., Sarró, S., Grácio, J., Martín-Carrasco, M., Martinez-Cabezón, A. C., . . . González-Fraile, E. (2018). Mental health professionals' attitudes towards mental illness: Professional and cultural factors in the INTER NOS study. European Archives of Psychiatry and Clinical Neuroscience. doi:10.1007/s00406-018-0867-5.

Parle, S. (2012). How does stigma affect people with mental illness?. Nursing times, 108(28), $12-14$

Peterson, J., Skeem, J. L., Hart, E., Vidal, S., \& Keith, F. (2010). Comparing the offense patterns of offenders with and without mental disorder: Exploring the criminalization hypothesis. Psychiatric Services, 61, 1217-1222.

doi:10.1176/appi.ps.61.12.1217Peterson, J. K., Skeem, J., Kennealy, P., Bray, B., \&

Zvonkovic, A. (2014). How often and how consistently do symptoms directly precede criminal behavior among offenders with mental illness?. Law and human behavior, 38(5), 439.

Pondé, M. P., Caron, J., Mendonça, M. S., Freire, A. C., \& Moreau, N. (2014). The Relationship Between Mental Disorders and Types of Crime in Inmates in a Brazilian Prison. Journal of Forensic Sciences, 59(5), 1307-1314. doi:10.1111/15564029.12462.

Reavley, N. J., \& Jorm, A. F. (2011). Stigmatizing attitudes towards people with mental disorders: findings from an Australian National Survey of Mental Health Literacy and Stigma. Australian and New Zealand Journal of Psychiatry, 45(12), 1086-1093.

Rose, D., Thornicroft, G., Pinfold, V., \& Kassam, A. (2007). 250 labels used to stigmatise people with mental illness. BMC Health Services Research, 7(1). doi:10.1186/14726963-7-97. 
Rueve, M. E., \& Welton, R. S. (2008). Violence and Mental Illness. Psychiatry (Edgmont), 5(5), 34-48. Retrieved from https://www.ncbi.nlm.nih.gov/pmc/articles/PMC2686644/.

Seymour, L. (2010), Public Health and Criminal Justice. Promoting and Protecting Offenders' Mental Health and Wellbeing. Retrieved from https://www.centreformentalhealth.org.uk/public-health-and-criminal-justice.

Silton, N. R., Flannelly, K. J., Milstein, G., \& Vaaler, M. L. (2011). Stigma in America: has anything changed?: Impact of perceptions of mental illness and dangerousness on the desire for social distance: 1996 and 2006. The Journal of nervous and mental disease, 199(6), 361-366.

Swanson, J. W., Holzer, C. E., Ganju, V. K., \& Jono, R. T. (1990). Violence and Psychiatric Disorder in the Community: Evidence From the Epidemiologic Catchment Area Surveys. Psychiatric Services, 41(7), 761-770. doi:10.1176/ps.41.7.761.

Swanson, J. W., Swartz, M. S., Essock, S. M., Osher, F. C., Wagner, H. R., Goodman, L. A., ... \& Meador, K. G. (2002). The social-environmental context of violent behavior in persons treated for severe mental illness. American Journal of Public Health, 92(9), $1523-1531$.

Taylor, P. J. (2008). Psychosis and violence: Stories, fears, and reality. Canadian Journal of Psychiatry, 53, 647-659.

Time to Change. (2015). Attitudes to Mental Illness 2014 Research Report. Retrieved from https://www.time-to-change.org.uk/news/latest-survey-shows-public-are-less-likelydiscriminate-against-people-mental-health-problems.

Torrey, E. F. (2011). Stigma and violence: Isn't it time to connect the dots? Schizophrenia Bulletin, 37. Advanced online publication. doi:10.1093/schbul/sbr057 
Torrey, E. F., Kennard, A. D., Eslinger, D., Lamb, R., \& Pavile, J. (2010). More mentally ill persons are in jails and prisons than hospitals. A survey of states. Arlington, VA: Treatment Advocacy Center. Retrieved from http://www.treatmentadvocacycenter.org/storage/documents/final_jails_v_hospitals_s tudy.pdf.

Van Dorn, R., Volavka, J., Johnson, N. (2012). Mental disorder and violence: Is there a relationship beyond substance use? Social Psychiatry and Psychiatric Epidemiology, 47, 487-503. doi:10.1007/s00127-011-0356-x.

Varshney, M., Mahapatra, A., Krishnan, V., Gupta, R., \& Deb, K. S. (2015). Violence and mental illness: What is the true story? Journal of Epidemiology and Community Health, 70(3), 223-225. doi:10.1136/jech-2015-205546.

Vinkers, D. J., de Beurs, E., Barendregt, M., Rinne, T., \& Hoek, H. W. (2011). The relationship between mental disorders and different types of crime. Criminal Behaviour and Mental Health, 21(5), 307-320. doi:10.1002/cbm.819.

Vinkers, D. J., de Beurs, E., Barendregt, M., Rinne, T., \& Hoek, H. W. (2012). Proportion of crimes attributable to mental disorders in the Netherlands population. World Psychiatry, 11(2), 134.

Walsh, E., Buchanan, A., \& Fahy, T. (2002). Violence and schizophrenia: Examining the evidence. British Journal of Psychiatry, 180(06), 490-495. doi:10.1192/bjp.180.6.490.

WHO. (1992). The ICD-10 Classification of Mental and Behavioural Disorders. Clinical Descriptions and Diagnostic Guidelines. World Health Organization: Geneva. Retrieved from http://apps.who.int/iris/handle/10665/37958.

Wood, L., Birtel, M., Alsawy, S., Pyle, M., \& Morrison, A. (2014). Public perceptions of stigma towards people with schizophrenia, depression, and anxiety. Psychiatry research, 220(1-2), 604-608. 
Yang, L. H., Anglin, D. M., Wonpat-Borja, A. J., Opler, M. G., Greenspoon, M., \& Corcoran, C. M. (2013). Public stigma associated with psychosis risk syndrome in a college population: implications for peer intervention. Psychiatric Services, 64(3), 284-288. 